\title{
EDITORIAL
}

\section{Obituary: Dr Max Harry Weil}

\author{
Jean-Louis Vincent
}

Critical care medicine has lost one of its true leaders, some would say its father-figure. Dr Max Harry Weil (Figure 1) played such a major role in the development of intensive care medicine as we know it today, making numerous contributions that have shaped the way in which we approach and manage critically ill patients.

Born in Switzerland, Dr Weil reached the US when he was just 10. He obtained his MD degree in New York in 1952, a PhD degree from the University of Minnesota in 1957, and an honorary ScD degree from the State University of New York in 2004. He worked for several years as a cardiologist before deciding to devote his time to critical care medicine.

As early as 1959 Dr Weil created the famous Shock Unit at the University of Southern California, and then in 1974 started an Institute of Critical Care Medicine. He moved to the University of Health Sciences in 1981 before returning to California in 2007 to create his own Institute - The Weil Institute of Critical Care Medicine in Rancho Mirage.

His major contributions are well known to all intensivists, and include improved understanding of the pathophysiology of shock states, of the importance of blood lactate levels, and of the mechanisms of lung edema including the role of colloid osmotic pressure. Many of today's management strategies and therapeutic approaches in critical care medicine are built on foundations put in place by Dr Weil, including the use of fluids (he developed the famous fluid challenge technique) and of vasoactive agents. In more recent years, his research focused on the microcirculation and on cardiopulmonary resuscitation, including monitoring techniques (for example, capnometry) and the role of various therapeutic agents. Not surprisingly, he was an important member of the Wolf Creek conferences on cardiopulmonary resuscitation.

As a physiologist and a professor in clinical biomedical engineering, as well as a physician, Dr Weil managed to combine aspects of medicine, physiology, pharmacology, biochemistry and bio-engineering for the benefit of the

*Correspondence: jlvincen@ulb.ac.be

Department of Intensive Care, Erasme Hospital, Free University of Brussels, Route de Lennik 808, B-1070 Brussels, Belgium

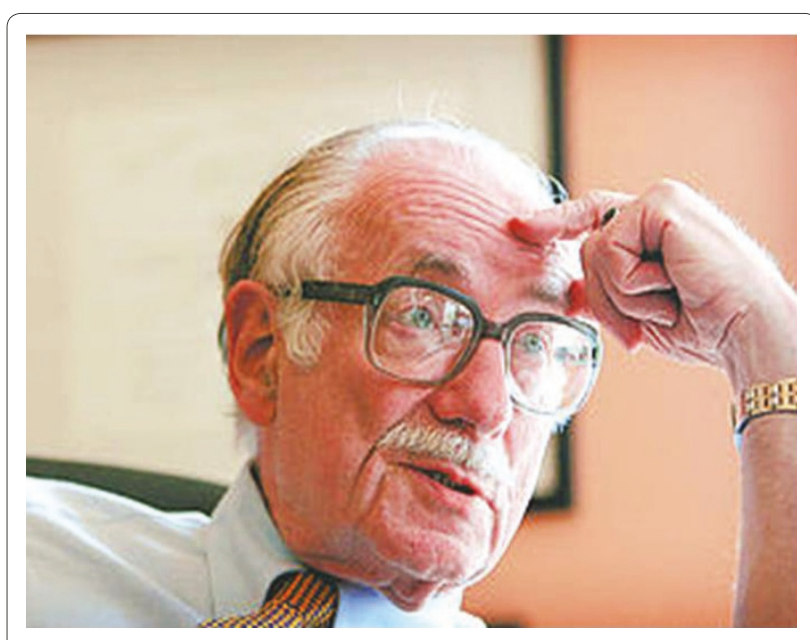

Figure 1. Dr Max Harry Weil.

critically ill. As an innovator and inventor, he owned more than 20 patents for medical equipment and devices he developed to help monitor and treat critically ill patients.

Dr Weil trained many hundreds of intensivists from the five continents and remained a faithful mentor to many, if not all, of us. Under his skilled tutorship and guidance, we learned the importance of basing our approach on pathophysiological alterations at the bedside, focusing on the individual patient. He always preferred discerning studies in a small number of patients to large randomized, controlled trials of heterogeneous groups.

Dr Weil was a founding member and the first President of the Society of Critical Care Medicine. He was a Master Fellow of the College of Chest Physicians, a Master of the American College of Physicians, and a Fellow of the American College of Cardiology, the Society of Critical Care Medicine, and the American Heart Association. He authored or co-authored more than 600 full peer-reviewed papers. He was actively involved in multiple committees and was a valued member of the editorial boards of many journals, including Critical Care. Dr Weil was widely respected and received awards from several International Societies and groups, including a Lifetime Achievement Award from the World Federation of Societies of Intensive and Critical Care Medicine in 2009. 
Dr Weil was highly intelligent, quick-thinking, and astute. When he asked you 'What are you up to these days?', you could be sure that by the second sentence of your reply he would already be one step ahead, offering insightful and thoughtful questions and suggestions for your latest project. His strong personality sometimes led to political conflicts: he liked to remind his friends of the trouble he encountered at the University of Southern California when he started inserting central venous catheters in patients. But along with his strength of character came an endearing personality and a truly kind nature - he was always interested not only in how your medical career was progressing but also in your personal and family life, empathic in moments of joy and sadness.

Dr Weil died peacefully at the age of 84 . True to character, he remained active right up until the last few days of his life. One important event he will miss is the 50th Weil Symposium on Critical Care Medicine due to be held in Las Vegas in April 2012. This will indeed be a big anniversary and the planned memorial service will provide the ideal occasion for us to remember his achievements and to pay our respects to this great friend and father of intensive care.

Competing interests

The author declares that he has no competing interests.

Published: 29 September 2011

doi:10.1186/cc10347

Cite this article as: Vincent JL: Obituary: Dr Max Harry Weil. Critical Care 2011, 15:192. 